\title{
Immune-induced angiotensin-converting enzyme assures the appearance of complementary peptides in Locusta migratoria for fine-tuning the innate immune response by inhibiting immune-activated phenoloxidase
}

\author{
Roger Huybrechts* and Luca Coltura \\ Laboratory of Insect Physiology and Molecular Ethology, Zoological Institute of KU Leuven, \\ Naamsestraat 59, 3000 Leuven, Belgium.
}

\begin{abstract}
Many insects express different isoforms of a single domain angiotensin-converting enzyme (ACE) orthologue. Insect somatic ACEs, as typical zinc metalloproteases, represent promiscuous dipeptidyl carboxypeptidases involved in neuropeptide processing and clearance and in yolk breakdown. Insect angiotensin converting enzymes regulate both developmental growth and reproduction. Insect ACEs function within the ecdysteroid pathway and ACE inhibitors open new ways of insect control. In Locusta migratoria, angiotensin converting enzyme expression by hemocytes is upregulated following immune challenge. Recently, its mode of action within the innate immune system was disclosed. Circulating Lom-ACE is involved in the appearance and clearance of immune-induced hemolymph peptides. Moreover, locmi-antimelanin-I peptide, a hexamerin-II processed and secreted peptide precursor that is further processed by Lom-ACE to an ACE-resistant peptide functions as inhibitor of immune-activated phenoloxidase. A second immune-induced and ACE-activated locmiantimelanin-II hemolymph 13-mer peptide, PGPLPQFQNKDEG, putatively originating from hemocyanin, was kinetically characterized as potent phenoloxidase inhibitor. In contrast to the known phenoloxidase inhibitor of the housefly, both the
\end{abstract}

\footnotetext{
*Email id: Roger.Huybrechts@kuleuven.be
}

Locusta migratoria-derived anti-melanins lack a high cysteine content. Locmi-antimelanin-II, a non-competitive inhibitor, efficiently inactivates phenoloxidase with a calculated $\mathrm{Ki}$ of $149 \mu \mathrm{M}$. The predicted overall similarity in 3-D structure and the kinetic characteristics of both Locmiantimelanin-I and Locmi-antimelanin-II suggest their complementary in vivo action.

KEYWORDS: locmi-antimelanin-II, inhibition kinetics, non-competitive inhibition, Lom-ACE, PPO.

\section{INTRODUCTION}

In medical context angiotensin-converting enzyme EC 3.4.15.1 represents a major target for blood pressure regulation $[1,2]$. On the other hand, the benefit of using angiotensin converting enzyme blockers in preventing inflammation and causing a reduction in high sensitive $\mathrm{C}$-reactive protein (hsCRP) levels by $21 \%$ to $32 \%$ is well documented [3]. In mammals, including man, sACE prevents the cytokine burst-associated risks by degrading pro-inflammatory cytokines and activating postinflammatory cytokines. The importance herein of angiotensin-converting enzyme, acting independent of the angiotensin pathway, indicates that angiotensinconverting enzyme has an evolutionary origin preceding RAAS [4, 5]. Indeed, in insects the occurrence of a functional sACE orthologue is evidenced since 1993 [6]. Since insects have an open blood circulation the regulation of their blood 
pressure is not an issue. Accordingly, an original function of sACE in neuropeptide processing has been put forward and experimentally evidenced [7-9]. Apart from the function of ACE in neuropeptide modulation in both the brain and the circulatory system, a variety of alternative functions for ACE within the insect are claimed. ACE accumulated in the eggs of the flesh fly helps in making amino acids available for the embryo $[10,11]$. ACE helps regulating protein meal digestion in Neobellieria bullata as it clears Neb-TMOF, a gut trypsinmodulating ovary-derived factor $[12,13]$. ACE regulates developmental growth and reproduction by modulating the ecdysteroid pathway. In imaginal discs the ACE expression itself depends upon ecdysteroids [14-17]. As many insects express ACE from multiple encoding genes [18] one can expect the different ACE isoforms to work in a stage and tissue-specific fashion [19].

In analogy with the insights in vertebrates regarding the involvement of sACE in inflammation, already in 2003 we noticed an immune challenge-induced increase in ACE expression by hemocytes of Locusta migratoria [20]. Accordingly, we launched the idea of somatic angiotensin-converting enzyme of insects having a primary role in innate immunity. However, understanding the true meaning of our observations took several years because of the apparent absence of typical vertebrate cytokines such as interleukins and interferons. Only in 2016 we demonstrated the role of ACE in both the appearance and degradation of immune-induced circulating peptides [21]. As a peptide, that we now call Locmi-antimelanin-I, was processed from a known immune active hexamerin-II precursor protein, we first explored the antibacterial and insect cell cycle regulating activities of this peptide, but all these initial efforts turned out to be unsuccessful so far. As, in insects, a primary role in initiating both the cellular and humoral innate immune response is dedicated to immune-activated prophenoloxidase (PPO-PO), it was of no surprise that the LPSinduced Locmi-antimelanin-I peptide, which only appears in the hemolymph in the presence of functional $\mathrm{ACE}$, turned out to be a downregulator of phenoloxidase (PO) [22].

In the hope of finding additional evidence for our claim about the evolutionary conserved role of ACE in fine-tuning the innate immune response via activation and inactivation of immune-induced peptides and having at hand the simple phenoloxidase inhibition assay, we continued our screening. A 13-mer peptide, PGPLPQFQNKDEG that was upregulated by LPS challenge and also depended upon ACE functionality, turned out to be a strong circulating non-competitive phenoloxidase inhibitor. Accordingly, we named this hemolymph peptide Locmi-antimelanin-II. In this manuscript, we elaborate upon the phenoloxidase-inhibiting characteristics and discuss the importance of this Locmiantimelanin-II peptide in view of the immune homeostasis in Locusta migratoria.

\section{MATERIALS AND METHODS}

Gregarious Locusta migratoria were reared under controlled conditions with regard to relative humidity (40-60\%), photoperiod (13 hours light) and temperature $\left(32+/-1{ }^{\circ} \mathrm{C}\right)$. They were housed in ventilated cages $(0.5 \mathrm{~m} \times 0.5 \mathrm{~m} \times 0.5 \mathrm{~m})$ at high density (100-200 animals per cage) to assure crowded conditions. We obtained the locusts from Sprinkhanenwinkel.com in The Netherlands using express mailing. Upon arrival, the adult locusts, aged 3 days ( $+/-24 \mathrm{hrs})$, were used for 2 subsequent weeks. Only males were used in the experiments and within each experiment, all animals had similar age.

Following $\mathrm{CO}_{2}$ anesthesia and distal amputation of a leg from the mesothorax, $10 \mu$ l hemolymph was withdrawn using a micropipette. To avoid coagulation, hemolymph was diluted by instant mixing with 10-fold excess of cold anticoagulants buffer (17 mM EDTA, $41 \mathrm{mM}$ citric acid, $186 \mathrm{mM}$ $\mathrm{NaCl}$ and $98 \mathrm{mM} \mathrm{NaOH}$, pH 4.5).

For preparation of the phenoloxidase stock, freshly collected pooled hemolymph $(\mathrm{n}=3)$ was immediately diluted (5:95 v:v) in ice-cold $10 \mu \mathrm{M}$ potassium phosphate buffer, pH 5.9 and kept on ice until pelleting the hemocytes $\left(4^{\circ} \mathrm{C}, 10 \mathrm{~K} \mathrm{rpm}\right.$, 5 minutes). Equal volumes of cell-free diluted hemolymph and absolute methanol were mixed in order to maximally activate the prophenoloxidase [23]. 3mg/ml L-Dopa (Sigma-Aldrich, Belgium) was freshly dissolved in $10 \mu \mathrm{M}$ potassium phosphate buffer, $\mathrm{pH} 5.9$ and kept protected from light. Using polystyrene microtiter plates $100 \mu$ l peptide solution in a serial dilution series and $20 \mu \mathrm{l}$ of activated PO were pre-incubated for 30 minutes after which $180 \mu 1$ of L-Dopa substrate was added. The measurement of 
absorbance change at 90 seconds intervals was started immediately and continued for 33 cycles at $495 \mathrm{~nm}$ using Tecan Infinite 200 multiplate reader. Dopachrome concentrations were calculated using an extinction coefficient of $3600 \mathrm{~m}^{-1} \mathrm{~cm}^{-1}$ and path length of $6.22 \mathrm{~mm}$. For kinetics analysis and calculation of inhibition constant of Locmiantimelanin-II the assay was performed using variable substrate concentrations ranging from $2.5 \mathrm{mM}$ up to $15 \mathrm{mM}$ whereas now the peptide concentration was kept constant at $250 \mu \mathrm{M}$. All enzyme reactions were done in triplicate and repeated by independent researchers. Average numbers obtained within single experiments were used to calculate and draw the graphics. GraphPad library of nonlinear regression models was used to fit data sets. The Michaelis-Menten enzyme kinetics model included in the GraphPad software was used. For LineweaverBurk plots linear regression with extrapolation to the $\mathrm{x}$-axis was applied.

The 13-mer peptide with sequence PGPLPQFQ NKDEG, as recently identified in our team [21] was synthetized at GL Biochem (Shanghai). In all experiments, initiated for calculating enzyme kinetics, a $98 \%$ high pressure liquid chromatography- purified peptide was used. All other chemicals were obtained from Sigma Aldrich-Belgium.

For de novo peptide 3-D modeling the Locmiantimelanin-I and Locmi antimelanin-II sequences were submitted online to the Pep-fold server at Paris University-Diderot using Pep-fold 3.5 algorithms. (bioserv.rpbs.univ-paris-diderot.fr/services/PEPFOLD/) [24, 25].

\section{RESULTS}

Using a serial dilution of the 13-mer peptide under investigation, a clear dose response in inhibiting phenoloxidase activity was evidenced within the range of $1 \mathrm{mM}$ down to $62 \mu \mathrm{M}$ (Fig. 1).

Using a standard amount of hemolymph-derived and methanol-activated phenoloxidase, whilst using a constant amount of inhibitor concentration $(250 \mu \mathrm{M})$ in the presence of increasing amounts of L-Dopa substrate, Michaelis Menten kinetics (Fig. 2) and Lineweaver-Burk plots (Fig. 3) were graphically assembled.

The inhibition constant, representing the inhibitor concentration that results in half of the maximal inhibition was calculated to be $149 \mu \mathrm{M}$. The mechanism of inhibition, based upon comparing $\mathrm{Km}$ values in the presence $\left(\mathrm{Km}_{\mathrm{i}}\right)$ and absence $\left(\mathrm{Km}_{\mathrm{c}}\right)$ of inhibitor ranges between mixed inhibition and non-competitive inhibition $\left(\mathrm{Km}_{\mathrm{i}} \geq \mathrm{Km}_{\mathrm{i}}\right.$ ) As both lines calculated in the presence and absence of inhibiting Locmi-antimelanin-II peptide cross the $\mathrm{X}$-axis at almost identical place and in combination with the reduced Vmaxi values, a non-competitive inhibition mechanism is proposed.

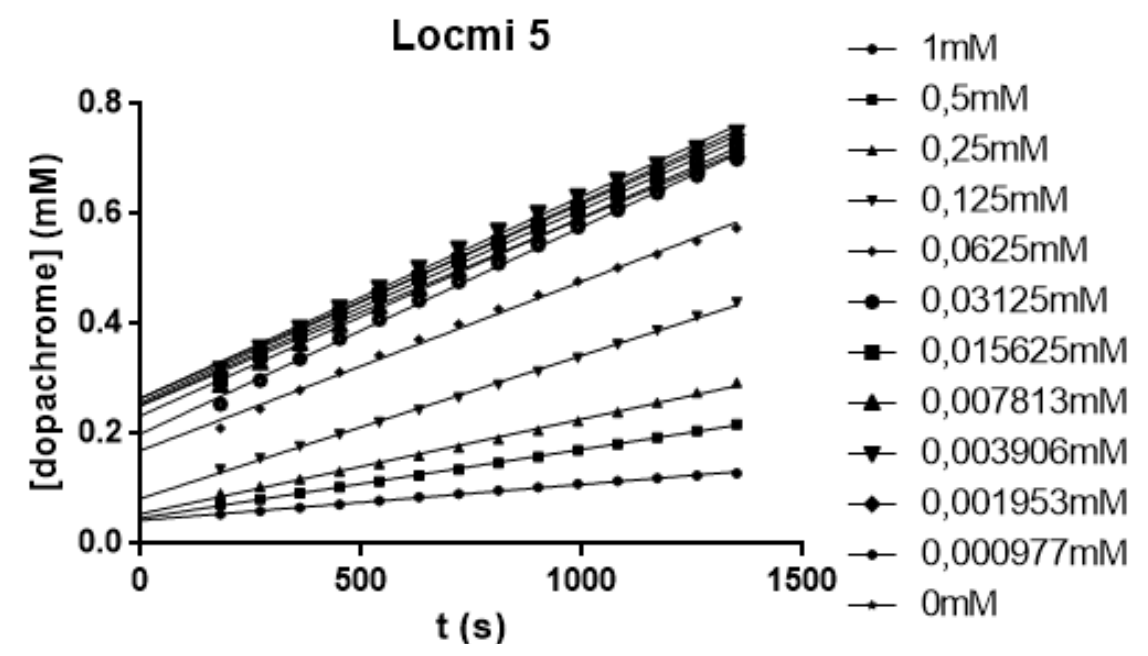

Fig. 1. Dose-dependent inhibition of phenoloxidase as intermittently measured over a 24 minutes time window. Each data point represents the average of 3 independent reactions. The PO enzyme activity was kept constant in all reaction mixes. Standard deviation of these triplicates was too small for graphical representation. 


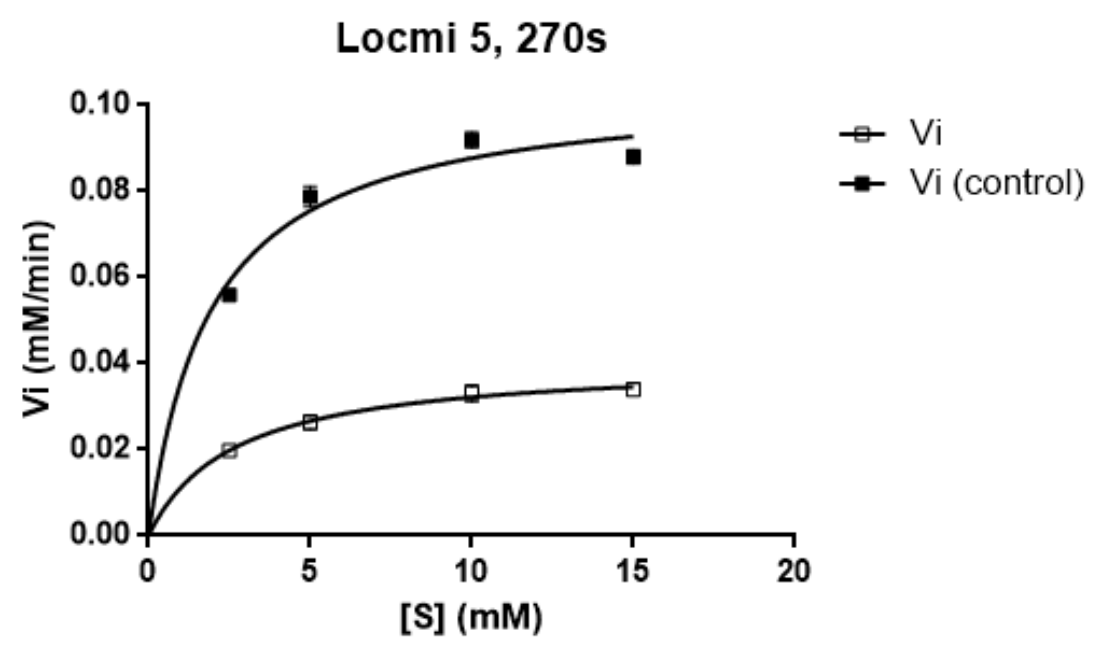

Fig. 2. Michaelis-Menten representation of the dopachrome production by phenoloxidase using increasing amounts of L-Dopa substrate. In the presence of Locmi-antimelanin-II Vmax is markedly reduced. Data points represent the average of 3 independent measurements at 270 seconds following substrate addition. $\mathrm{Vi}=$ initial reaction velocity.

\section{Locmi 5, 270s}

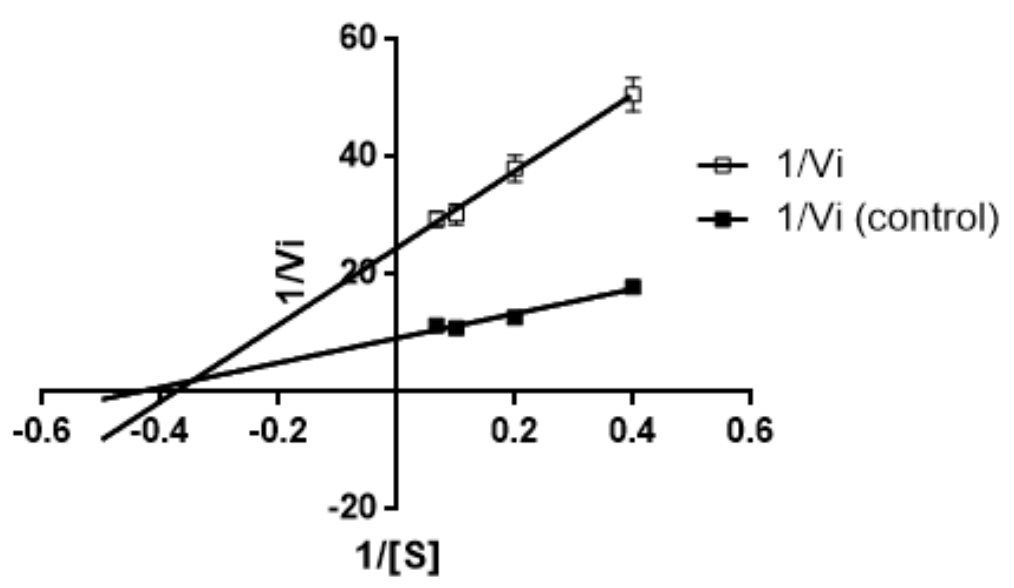

Fig. 3. Line Weaver-Burk representation of the same data as displayed in Fig. 2.

Structural comparison of both our earlier identified Locmi-antimelanin-I and the herein identified Locmi-antimelanin-II, although not sharing sequence similarity, remarkably share structural resemblance. They form either a C-terminal single or a double helicoïdal looping and both have an N-terminal overlaying flap (Fig. 4).

\section{DISCUSSION}

In contrast to the first identified endogenous dopacontaining PO inhibitor of the housefly Musca domestica [26] neither the herein reported inhibitor Locmi-antimelanin-II nor the previously reported Locmi-antimelanin-I are rich in cysteine [22]. Both PO inhibitors, as isolated from the hemolymph of immunized Locusta migratoria having their ACE enzyme fully active, represent non-competitive and uncompetitive inhibitors, respectively. They both preferentially interact with the established enzyme substrate complex and minimally compete with the enzyme substrate interaction. Based upon kinetic performance, in comparison to Locmi-antimelanin-I, 


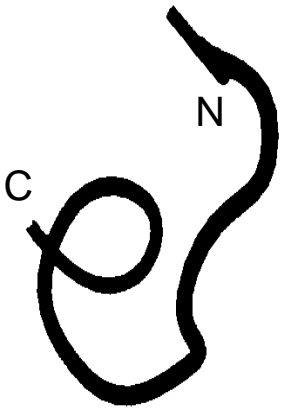

AVVPHSEAGKEL

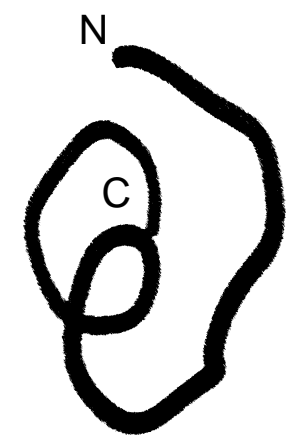

PGPLPQFQNKDEG
Fig. 4. 3-D models of Locmi-antimelanin-I (left) and Locmi-antimelanin-II (right) peptide as generated by the Pep-fold 3.5 algorithm for peptide structure prediction [24, 25].

the herein characterized Locmi-antimelanin-II 13mer peptide PGPLPQFQNKDEG can be expected to work complementary as lower amounts are needed for rapid inhibition whilst the slower acting Locmi-antimelanin-I will be more effective in terms of maximal downregulating effect.

It is clear that a strict regulation of the phenoloxidase activity in the insect circulation system is crucial for survival in both insect and crustaceans as it plays a demonstrated but still undefined role in the correct execution of both humoral as well as the cellular defense barrier [27, 28]. Indeed, activation of the harmless circulating prophenoloxidase (PPO) into phenoloxidase (PO) is strictly regulated via serine protease intervention [29-31]. In addition, our experiments underline that it is as well important to downregulate the activated phenoloxidase. Hereto, immune-induced angiotensin-converting enzyme activates a multitude of secreted peptides displaying phenoloxidaseinhibiting activity. The data, generated by our previous differential peptidomics approach in a condition that mirrored immune challenge in combination with functional angiotensin-converting enzyme depletion [21], underline that the insect SACE is responsible both for the rapid activation of post-inflammation-acting peptides as well as for the rapid clearance of pre-inflammatory peptides from circulation. On the other hand, the herein described experiments do not exclude infectioninduced appearance in circulation of a plethora of ACE-independent peptides displaying similar PO inhibiting activity, but again we can expect the latter type of peptides being vulnerable for ACE degradation, which again makes the role of ACE as regulator of the initial innate immune steps even more prominent.

\section{CONCLUSION}

Locmi-antimelanin-II, working in complement with Locmi-antimelanin-I, inhibits immune-activated phenoloxidase and prevents the risks accompanying the otherwise uncontrolled melanisation reaction.

\section{ACKNOWLEDGEMENT}

The authors thank Evelien Herinckx for taking care of the Locusta migratoria stock. Els Wellens is acknowledged for proofreading and editing the manuscript.

\section{CONFLICT OF INTEREST STATEMENT}

There are no conflicts of interest.

\section{REFERENCES}

1. Xie, W., Zheng, F., Evangelou, E., Liu, O., Yang, Z., Chan, Q., Elliott, P. and $\mathrm{Wu}, \mathrm{Y}$. 2018, J. Hypertens., 36, 1256-1265. doi: 10.1097/HJH.0000000000001720

2. Fyhrquist, F. and Saijonmaa, O. 2008, J. Intern. Med., 264, 224-36. doi: 10.1111/ j.1365-2796.2008.01981.x

3. Martinez, B. K. and White, C. M. 2018, Ann. Pharmacother., 1, 1060028018765939. doi: 10.1177/1060028018765939 [Epub ahead of print].

4. Bernstein, K. E., Ong, F. S., Blackwell, W. L., Shah, K. H., Giani, J. F., GonzalezVillalobos, R. A., Shen, X. Z., Fuchs, S. and Touyz, R. M. 2012, Pharmacol. Rev., 65(1), 1-46. doi: 10.1124/pr.112.006809 (Erratum in: Pharmacol. Rev. 2013, 65, 544).

5. Crowley, S. D. and Rudemiller, N. P. 2017, Am. Soc. Nephrol., 5, 1350-1361. doi: 10.1681/ASN.2016101066

6. Lamango, N. and Isaac, R. E. 1993, Biochem. Soc. Trans., 21, 245S.

7. Isaac, R., Schoofs, L., Williams, T. A., Veelaert, D., Sajid, M., Corvol, P. and Coates, D. 1998, Biochem. J., 330, 61-5. 
8. Isaac, R. E., Bland, N. D. and Shirras, A. D. 2009, Gen. Comp. Endocrinol., 162, 8-17. doi: 10.1016/j.ygcen.2008.12.011

9. Schoofs, L., Veelaert, D., De Loof, A., Huybrechts, R. and Isaac E. 1998, Brain Res., 785, 215-27.

10. Vandingenen, A., Hens, K., Baggerman, G., Macours, N., Schoofs, L., De Loof, A. and Huybrechts, R. 2002, Peptides, 23, 1853-63.

11. Hens, K., Vandingenen, A., Macours, N., Baggerman, G., Karaoglanovic, A. C., Schoofs, L., De Loof, A. and Huybrechts, R. 2002, Eur. J. Biochem., 69, 3522-30.

12. Vandingenen, A., Hens, K., Macours, N., Zhu, W., Janssen, I., Breuer, M., De Loof, A. and Huybrechts, R. 2001, Arch. Insect Biochem. Physiol., 47, 161-167.

13. Zhu, W., Vandingenen, A., Huybrechts, R., Baggerman, G., De Loof, A., Poulos, C., Velentza, A. and Breuer M. 2002, Insect Biochem. Mol. Biol., 31, 87-95.

14. Vercruysse, L., Gelman, D., van de Velde, S., Raes, E., Hooghe, B., Vermeirssen, V., van Camp, J. and Smagghe, G. 2005, Ann. NY. Acad. Sci., 1040, 498-500.

15. Soltani-Mazouni, N., Bouteldja, D., Lemeire, E. and Smagghe, G. 2007, Commun. Agric. Appl. Biol. Sci., 72, 623-7.

16. Siviter, R. J., Taylor, C. A., Cottam, D. M., Denton, A., Dani, M. P., Milner, M. J., Shirras, A. D. and Isaac, R. E. 2002, Biochem. J., 367, 187-93.

17. Quan, G. X., Mita, K., Okano, K., Shimada, T., Ugajin, N., Xia, Z., Goto, N., Kanke, E. and Kawasaki, H. 2001, Insect. Biochem. Mol. Biol., 31, 97-103.

18. Burnham, S., Smith, J. A., Lee, A. J., Isaac, R. E. and Shirras, A. D. 2005, BMC Genomics, 5,172 .

19. Yan, H. Y., Mita, K., Zhao, X., Tanaka, Y., Moriyama, M., Wang, H., Iwanaga, M. and
Kawasaki, H. 2017, Gene, 608, 58-65. doi: 10.1016/j.gene.2017.01.017

20. Macours, N., Hens, K., Francis, C., De Loof, A. and Huybrechts, R. 2003, J. Insect Physiol., 49, 739-46.

21. Duressa, T. F., Boonen, K. and Huybrechts, R. 2016, Gen. Comp. Endocrinol., 235, 120-129.

22. Huybrechts, R., Coltura, L. Ickx, S. and Duressa, T. 2018, Japan Journal of Medicine, 1, 122-129, doi xxx/jjm.105

23. Mullen, L. and Goldsworthy, G. 2003, Insect Biochem. Mol. Biol., 33, 661-70.

24. Alland, C., Moreews, F., Boens, D., Carpentier, M., Chiusa, S., Lonquety, M., Renault, N., Wong, Y., Cantalloube, H., Chomilier, J., Hochez, J., Pothier, J., Villoutreix, B. O., Zagury, J. F. and Tufféry, P. 2005, Nucleic Acids Res., 2005, 33(Web Server issue), W44-9.

25. Néron, B., Ménager, H., Maufrais, C., Joly, N., Maupetit, J., Letort, S., Carrere, S., Tuffery, P. and Letondal, C. 2009, Bioinformatics, 25, 3005-11.

26. Daquinag, A. C., Nakamura, S., Takao, T. and Shimonishi, Y. and Tsukamoto, T. 1995, Proc. Natl. Acad. Sci. USA, 92, 2964-8.27.

27. Amparyup, P., Charoensapsri, W. and Tassanakajon, A. 2013, Fish Shellfish Immunol., 34, 990-1001.

28. Wang, Y., Jiang, H., Cheng, Y., An, C., Chu, Y., Raikhel, A. S. and Zou, Z. 2017, Insect Mol. Biol., 26, 552-563.

29. Cerenius, L. and Söderhäll, K. 2004, Immunol. Rev., 198, 116-26.

30. Lu, A., Zhang, Q., Zhang, J., Yang, B., Wu, K., Xie, W., Luan, Y. X. and Ling, E. 2014, Front. Physiol., 5, 252.

31. Zhang, H., Tang, B., Lin, Y., Chen, Z., Zhang, X., Ji, T., Zhang, X. and Hou Y. 2017, Arch Insect Biochem. Physiol., 96. doi: 10.1002/arch. 21425 